Article

\title{
Organization of Bone Mineral: The Role of Mineral-Water Interactions
}

\author{
Stanislas Von Euw ${ }^{1, *,+} \mathbb{0}$, Tsou-Hsi-Camille Chan-Chang ${ }^{1}$, Caroline Paquis ${ }^{1}$, Bernard Haye ${ }^{1}$, \\ Gérard Pehau-Arnaudet ${ }^{2}$, Florence Babonneau ${ }^{1}{ }^{1}$, Thierry Azaïs ${ }^{1}$ and Nadine Nassif ${ }^{1}$ \\ 1 CNRS, Collège de France, Laboratoire de Chimie de la Matière Condensée de Paris (LCMCP), \\ Sorbonne Université, 4 place Jussieu, F-75005 Paris, France; tsou.chan_chang@etu.upmc.fr (T.-H.-C.C.-C.); \\ carolinepaquis@gmail.com (C.P.); bernard.haye@upmc.fr (B.H.); florence.babonneau@upmc.fr (F.B.); \\ thierry.azais@upmc.fr (T.A.); nadine.nassif@upmc.fr (N.N.) \\ 2 UMR 3528 and UTech UBI, Institut Pasteur, 28 rue du Docteur Roux, F-75015 Paris, France; \\ gerard.pehau-arnaudet@pasteur.fr \\ * Correspondence: voneuws@tcd.ie \\ + Current address: Trinity Centre for Bioengineering, Trinity Biomedical Sciences Institute, Trinity College \\ Dublin (TCD), Dublin 2, D02 R590, Ireland.
}

Received: 10 November 2018; Accepted: 1 December 2018; Published: 8 December 2018

\begin{abstract}
The mechanism (s) that drive the organization of bone mineral throughout the bone extracellular matrix remain unclear. The long-standing theory implicates the organic matrix, namely specific non-collagenous proteins and/or collagen fibrils, while a recent theory proposes a self-assembly mechanism. Applying a combination of spectroscopic and microscopic techniques in wet and dry conditions to bone-like hydroxyapatite nanoparticles that were used as a proxy for bone mineral, we confirm that mature bone mineral particles have the capacity to self-assemble into organized structures. A large quantity of water is present at the surface of bone mineral due to the presence of a hydrophilic, amorphous surface layer that coats bone mineral nanoparticles. These water molecules must not only be strongly bound to the surface of bone mineral in the form of a rigid hydration shell, but they must also be trapped within the amorphous surface layer. Cohesive forces between these water molecules present at the mineral-mineral interface not only hold the mature bone mineral particles together, but also promote their oriented stacking. This intrinsic ability of mature bone mineral particles to organize themselves without recourse to the organic matrix forms the foundation for the development of the next generation of orthopedic biomaterials.
\end{abstract}

Keywords: bone mineral; bone biomineralization; bone hydroxyapatite; bone mineral organization; amorphous surface layer; solid-state NMR; cryogenic TEM; mineral-water interactions

\section{Introduction}

Understanding the mechanism (s) that drive the organization of mature bone mineral nanoparticles throughout the bone extracellular matrix is a long-standing objective [1-4]. It will not only enhance our understanding of bone biomineralization, but will also provide design principles for the next generation of alloplasts for bone regeneration. Although bone mineral nanoparticles may be needle-shaped at early stages [5], mature bone mineral nanoparticles are in the form of elongated platelets with irregular shapes and dimensions [5-8]: 1-5 nm in thickness, $10-40 \mathrm{~nm}$ in width, and $\sim 20-100 \mathrm{~nm}$ in length. Their internal chemical composition and structure is in the form of hydroxyl-deficient $[9,10]$ carbonated [11,12] hydroxyapatite [13] with a hexagonal crystalline structure [14]. In contrast, they possess a distinct surface layer that can be described as hydrated $[15,16]$ and rich in monohydrogen-phosphate ions [17], whose chemical structure is analogous to amorphous 
calcium phosphate (ACP) [18]. About half of the volume of bone mineral platelets is not in the form of hydroxyapatite, since roughly $50 \%$ of the inorganic phosphate ions that compose them are present within the amorphous surface layer $[19,20]$. Further, the platelet morphology does not reflect the hexagonal symmetry of hydroxyapatite. Hence, it makes no sense here to use Miller indices notation for denoting crystal planes, as it would wrongly suggest that they are single crystals. Accordingly, we considered these bone mineral platelets as simple geometrical objects to describe their organization. Throughout the bone extracellular matrix, the elongated direction of the mineral platelets is preferentially aligned over micrometers along the long axis of the type I collagen fibrils [5,21-23] that compose the extracellular organic matrix together with different types of biomacromolecules. Locally, but sometimes also over tens of nanometers or more, the mineral platelets are not only aligned with each other but are also arranged side-by-side, respectively parallel and perpendicular to their elongated direction. In such a configuration, the largest side faces of the platelets are facing each other, while their smallest side faces together with their basal faces are where adjacent platelets presumably assemble to form "a mosaic composed of interlocking crystal tiles" [24]. This organization model, which is sometimes described as a "deck of cards" [25] or a "brick wall" [26] structure, is a satisfying approximation but is oversimplified, since slight misorientations of the mineral platelets occur both parallel [25] and perpendicular [27] to their elongated direction.

Regarding the mechanism (s) that drive this organization, the long-standing theory implicates the extracellular organic matrix. The earliest scenario depicts the action of specific endogenous biomacromolecules: the non-collagenous proteins (NCPs), and especially those that possess a regular secondary structure. Among them, dentin matrix protein 1 (DMP-1), whose C-terminal domain adopts a $\beta$-sheet secondary structure once bound with calcium ions [28], has raised particular interest. It was shown that, in vitro, DMP-1 not only can template hydroxyapatite crystals' nucleation and growth [29], but also can induce their organization into "parallel arrays" [30,31]. In practice, this scenario supposes a template-induced nucleation of the mineral phase that is mediated by immobilized proteins whose nucleation sites are "arranged in a periodic pattern which matches lattice parameters of certain planes in the forming crystal" [26]. In such a configuration, it is proposed that the bone mineral precursors are periodically deposited along the organized backbone of the involved proteins, while successive epitaxial growth steps allow for their propagation throughout the bone extracellular matrix in an oriented manner. This mechanism was nicely illustrated by Elia Beniash [26] (Figure 8 in the cited article). However, this earliest scenario was questioned as soon as co-oriented bone-like mineral platelets were observed within type I collagen fibrils using a protocol devoid of NCPs [25]. In this in vitro model of bone biomineralization, a single achiral polymer was used as a proxy for NCPs for directing the mineralization process: poly- $(\alpha, \beta)$-DL-aspartic acid. Since this polymer does not possess a regular secondary structure, the authors of the study considered an alternative scenario in which "collagen serves as the primary template of crystal orientation" [25]. This alternative scenario was later confirmed by other groups in additional studies [32-37], especially when the co-orientation of bone-like mineral platelets within a network of type I collagen fibrils in a very similar manner to that observed in bone was achieved in the absence of NCPs or polymer additives [38]. How type I collagen drives the long-range uniaxial orientation of bone and bone-like mineral platelets in vivo and in vitro, respectively, was subject to discussion. The role of the stereochemical configuration of fibrillar type I collagen in or near its gap and overlap zones, that is "the composition and location of its specific amino acid residues and charges" [39], has been pointed out [40]. It was identified early on as "favorable for the induction of hydroxyapatite crystallization" [41], and was later described as "critical in directing apatite nucleation, crystal size and shape, orientation and alignment" [39]. Citrate molecules have also raised interest. It has not only been proposed that a significant amount of them are strongly bound to the surface of bone mineral nanoparticles [42], but it has also been suggested that they can link adjacent bone mineral nanoparticles together [43] in an oriented manner [44]. A simple confinement effect $[45,46]$ within the type I collagen fibrils may also be envisaged, since it was shown to drive 
the chemical structure of the mineral nanoparticles at their early stages of formation [20], while the "orientation of hydroxyapatite crystals can be achieved by confinement alone" [45].

Last, another unexpected scenario should also be considered, since it was recently proposed that interstitial water at the mineral-mineral interface not only induces the aggregation but also drives the organization of bone mineral nanoparticles [15]. This is particularly meaningful for the mineral structures external to the collagen fibrils, which may represent from approximately $30 \%$ [4] to $70 \%$ [21] of the mineral matrix, and for which collagen cannot directly serve as a template for their organization. Here, we aim to confirm that this last scenario occurs during bone biomineralization. To this end, various synthetic calcium phosphate samples with a different structure or morphology were investigated in aqueous media using a combination of electron imaging and solid-state nuclear magnetic resonance (NMR) spectroscopy. Among these synthetic samples, a bone-like hydroxyapatite sample was used as a proxy for mature bone mineral. Particularly, we not only show how water interacts with the distinct surface of bone mineral nanoparticles, but we also discuss the mechanism (s) that can lead to their organization without recourse to non-collagenous proteins, collagen, or citrate.

\section{Materials and Methods}

Nanosized platelet-shaped bone-like hydroxyapatite particles, named Carbonated HydroxyApatite (CHA), were obtained according to the protocol described by Nadine Nassif et al. [47] (referred to as HA-2 in the referenced article). Briefly, an aqueous reaction solution containing $110 \mathrm{mM} \mathrm{CaCl} 2 \cdot 2 \mathrm{H}_{2} \mathrm{O}, 33 \mathrm{mM} \mathrm{NaH} \mathrm{PO}_{4} \cdot \mathrm{H}_{2} \mathrm{O}$, and $33 \mathrm{mM} \mathrm{NaHCO}_{3}$ was prepared. The $\mathrm{pH}$ of this reaction solution was adjusted to 2.2 with a $1 \mathrm{M} \mathrm{HCl}$ aqueous solution added dropwise. Two flasks (35 mL, $50 \mathrm{~mm}$ in height) containing $20 \mathrm{~mL}$ of this reaction solution (covered by perforated Parafilm), together with a flask containing $8 \mathrm{~mL}$ of a $28 \% \mathrm{w} / \mathrm{w}$ ammonium hydroxide solution, were placed into a $1 \mathrm{~L}$ sealed beaker. The $\mathrm{pH}$ of the reaction solution gradually increases following the solubilization of the ammonia gas; this leads to the precipitation of CHA. After 6 days, the precipitate was centrifuged (6000 rpm, $10 \mathrm{~min}$ ), washed three times with deionized water, and then dried at $37^{\circ} \mathrm{C}$ for 7 days before characterization. Nanosized carbonated hydroxyapatite particles that are in the form of needles and rods with different lengths, named CHA-needle/rod, were also obtained. They were prepared following the same protocol except that the reaction solution was continuously mechanically agitated during precipitation. Last, synthetic monetite and brushite samples were purchased from commercial sources.

The solid-state nuclear magnetic resonance (NMR) spectroscopy experiments were conducted on a Bruker $300 \mathrm{MHz}$ Avance-III spectrometer (Bruker, Billerica, MA, USA) running Topspin software. Powdered samples were packed into $4.0 \mathrm{~mm}$ (o.d.) zirconia rotors and spun at $14 \mathrm{kHz}$ in a $4 \mathrm{BL}$ $\mathrm{CP} / \mathrm{MAS}{ }^{1} \mathrm{H} / \mathrm{BB}$ probe. In the two-dimensional (2D) $\left\{{ }^{1} \mathrm{H}\right\}{ }^{31} \mathrm{P}$ Heteronuclear Correlation (HetCor) NMR spectra, the ${ }^{1} \mathrm{H}$ relaxation delay was set to $2 \mathrm{~s}$; the contact time $\left(\mathrm{t}_{\mathrm{CP}}\right)$ was set to $10 \mathrm{~ms}$; and 128 scans were used in each $280 \mathrm{t} 1$ increment. ${ }^{1} \mathrm{H}$ chemical shifts were referenced to TetraMethylSilane (TMS) at $\delta^{1} \mathrm{H}=0.0 \mathrm{ppm}$, while ${ }^{31} \mathrm{P}$ chemical shifts were referenced to $\mathrm{H}_{3} \mathrm{PO}_{4}(85 \% \mathrm{w} / \mathrm{w}$ aqueous solution) at $\delta^{31} \mathrm{P}=0.0 \mathrm{ppm}$. As for the experiments in wet conditions, about $10 \mu \mathrm{L}$ of deionized water (CHA) or $\mathrm{pH} 4$ buffer solution (monetite and brushite) has been directly added to the rotor prior to analysis. For monetite and brushite, a $\mathrm{pH} 4$ buffer solution was used instead of deionized water to avoid their transformation. Transmission electron microscopy (TEM) investigations were performed with a FEI TECMAI G2 Spirit Twin electron microscope (Thermo Fisher/FEI, Hillsboro, OR, USA) operating at $120 \mathrm{kV}$. Powdered samples were first dispersed in anhydrous ethanol at a low concentration. A drop of the resulting dispersions was deposited on carbon-coated copper grids, and TEM investigations were performed after solvent evaporation. Regarding the CHA spherulites, they spontaneously form following the protocol described above. After 6 days of ammonia gas diffusion, the spherulites were gently collected, dried at $37^{\circ} \mathrm{C}$ for two weeks, encased in epoxy resin, and finally sectioned with an ultra-microtome into $\sim 80 \mathrm{~nm}$ thin sections that were deposited on copper grids. Cryogenic TEM investigations were performed with a Jeol 2010F microscope (JEOL Ltd., Tokyo, 
Japan) operating at $200 \mathrm{kV}$. Powdered samples were first suspended in deionized water at a high concentration. The resulting suspensions were sonicated for $10 \mathrm{~min}$, placed under gentle stirring for $1 \mathrm{~h}$, and one drop was deposited on carbon-coated copper grids. The grids were cryofixed in liquid ethane using a cryo-fixation device (EMGP-Leica, Wetzlar, Germany), and then transferred inside the microscope with a 626DH cryoholder (Gatan, Pleasanton, CA, USA).

\section{Results}

A synthetic bone-like hydroxyapatite sample precipitated from in-vivo-inspired conditions [47], named Carbonated HydroxyApatite (CHA), has been used as a proxy for bone mineral. As mature bone mineral nanoparticles, $\mathrm{CHA}$ is in the form of elongated platelets with irregular shapes and dimensions according to transmission electron microscopy (TEM) observations (Figure 1). The platelets were here dispersed in anhydrous ethanol at a low concentration, deposited on a copper grid, dried at ambient temperature, and then observed under vacuum. This experiment was, therefore, performed far from in vivo conditions in terms of hydration but allows for the observation of well-dispersed individual platelets whose largest side faces are exposed. Atomic-scale spatial proximities between phosphorus-bearing ions and hydrogen-bearing ions and/or molecules in CHA were probed using solid-state nuclear magnetic resonance (NMR) spectroscopy. To this end, we used the two-dimensional (2D) $\left\{{ }^{1} \mathrm{H}\right\}^{31} \mathrm{P}$ Heteronuclear Correlation (HetCor) NMR experiment (Figure 2). In this experiment, the atomic-scale spatial proximities are detected as correlation peaks in the 2D $\left\{{ }^{1} \mathrm{H}\right\}{ }^{31} \mathrm{P}$ HetCor NMR spectra (Figure 2A,B), in which the phosphorus-bearing ions (displayed along the horizontal (F2) dimension) are correlated with their respective hydrogen-bearing ions or molecules (displayed along the vertical (F1) dimension, whose normalized ${ }^{1} \mathrm{H}$ projections are shown in Figure $2 \mathrm{C}, \mathrm{D}$ ). A special rotor, which was equipped with Teflon inserts, was used to study CHA soaked in water with the aim of mimicking the hydration conditions found in a fresh and fully hydrated bone tissue sample [15] (Figure 2A,C). In such conditions, the presence of two correlation peaks observable at $2.9 \mathrm{ppm}$ in the $\mathrm{F} 1\left({ }^{1} \mathrm{H}\right)$ dimension shows the presence of at least two different hydrogen-bearing ions or molecules in CHA. According to their chemical shifts in the $\mathrm{F} 1\left({ }^{1} \mathrm{H}\right)$ dimension, the two peaks can, respectively, be attributed to $\mathrm{OH}^{-}$ions (observable at $\delta^{1} \mathrm{H}=0.0 \mathrm{ppm}$ ) and a large quantity of water molecules (observable at $\delta^{1} \mathrm{H}=4.9 \mathrm{ppm}$ ). The sums of the $\mathrm{F} 2$ slices taken at the $\mathrm{OH}^{-}$ions and water molecules positions in $\mathrm{F} 1$ reveal their respective ${ }^{31} \mathrm{P}$ chemical environments (Figure $\mathrm{S} 1$ ). The phosphorus-bearing ions nearby $\mathrm{OH}^{-}$appear in the form of a narrow resonance centered at around $3 \mathrm{ppm}$, while the phosphorus-bearing ions nearby the large quantity of water are in the form of a much broader resonance also centered at around $3 \mathrm{ppm}$. Regarding the upper correlation peak, since its corresponding ${ }^{31} \mathrm{P}$ chemical environments are in the form of a narrow ${ }^{31} \mathrm{P}$ NMR resonance, and a proton chemical shift of $0.0 \mathrm{ppm}$ for $\mathrm{OH}^{-}$is typical of hydroxyapatite [48], this demonstrates that it can be attributed to $\mathrm{HO}^{-}$ ions near $\mathrm{PO}_{4}{ }^{3-}$ ions within the hydroxyapatite's crystal lattice of the crystalline nanoparticle core [19]. In contrast, regarding the lower correlation peak, since its corresponding ${ }^{31} \mathrm{P}$ chemical environments are in the form of a broad ${ }^{31} \mathrm{P} N \mathrm{~N}$ resonance that closely resembles the ${ }^{31} \mathrm{P}$ NMR resonance of a synthetic amorphous calcium phosphate (ACP) sample [15], it can be attributed to water molecules strongly bound to phosphorus-bearing ions in the amorphous surface layer. Further, when CHA is investigated in dry conditions, which is again far from in vivo conditions in terms of hydration, the $\mathrm{OH}^{-}$signal is unchanged while the sharp and intense signal of the water molecules strongly bound to the amorphous surface layer is no longer detected (Figure 2B,D). Instead, a broad and less intense composite signal that spreads along the $\mathrm{F} 1\left({ }^{1} \mathrm{H}\right)$ dimension from $\delta^{1} \mathrm{H}=5.5 \mathrm{ppm}$ to $\delta^{1} \mathrm{H}=7-15 \mathrm{ppm}$ is now observable. This signal can respectively be attributed to residual structural water molecules and monohydrogen-phosphate ions. These structural water molecules and $\mathrm{HPO}_{4}{ }^{2-}$ ions, together with $\mathrm{CO}_{3}{ }^{2-}$ and $\mathrm{Ca}^{2+}$ ions [15], compose the amorphous surface layer [18] of CHA platelets. Note that the 2D $\left\{{ }^{1} \mathrm{H}\right\}{ }^{31} \mathrm{P}$ HetCor NMR spectra of CHA in wet and dry conditions closely resemble the spectra of, respectively, fresh and dehydrated two-year-old sheep bone tissue samples [15]; this confirms that $\mathrm{CHA}$ is a bone-like hydroxyapatite. The different proton signals associated with the amorphous 
surface layer that are observed in the F1 $\left({ }^{1} \mathrm{H}\right)$ dimensions of the $2 \mathrm{D}\left\{{ }^{1} \mathrm{H}\right\}{ }^{31} \mathrm{P}$ HetCor NMR spectra when recorded in wet or dry conditions must be discussed. We assume that, in wet conditions, fast chemical exchanges occur between the protons from the surface- $\mathrm{HPO}_{4}{ }^{2-}$ ions and those from the free water molecules. Considering that there is an excess of free water molecules compared to the surface- $\mathrm{HPO}_{4}{ }^{2-}$ ions, the surface- $\mathrm{HPO}_{4}{ }^{2-}$ ions are "invisible" in wet conditions (a fast exchange regime) since only the signal of excess water is observed at $\delta^{1} \mathrm{H}=4.9 \mathrm{ppm}$. In contrast, in dry conditions, the fast ${ }^{1} \mathrm{H}$-chemical exchanges are quenched, and the surface- $\mathrm{HPO}_{4}{ }^{2-}$ ions are observable in the form of a broad signal in the range of $\delta^{1} \mathrm{H}=7-15 \mathrm{ppm}$. Moreover, since the drying process is manifestly not complete, very strongly bonded water molecules, here named residual structural water molecules, are also observed at $\delta^{1} \mathrm{H}=5.5 \mathrm{ppm}$. The present experiments also show that the presence of free water deeply affects the amorphous surface layer, while the crystalline nanoparticle core seems to be unaltered. This is not only observable in the ${ }^{1} \mathrm{H}$ chemical environments as described above, but also in the ${ }^{31} \mathrm{P}$ chemical environments. Again, but now in dry conditions, the sum of the F2 slices taken at the $\mathrm{OH}^{-}$ ions position in $\mathrm{F} 1$ reveal the individual ${ }^{31} \mathrm{P}$ signal of the crystalline nanoparticle core, while the sum of the F2 slices taken at the structural water molecules together with $\mathrm{HPO}_{4}{ }^{2-}$ ions position in $\mathrm{F} 1$ reveal the individual ${ }^{31} \mathrm{P}$ signal of the amorphous surface layer (Figure S1). The individual signals of the crystalline nanoparticle core are indistinguishable in wet and dry conditions, whereas the individual signal of the hydrated amorphous surface layer not only becomes broader (the full width at half maximum (FWHM) evolves from 2.6 ppm (dry) to 3.7 ppm (wet)) but also slightly asymmetric in wet conditions.

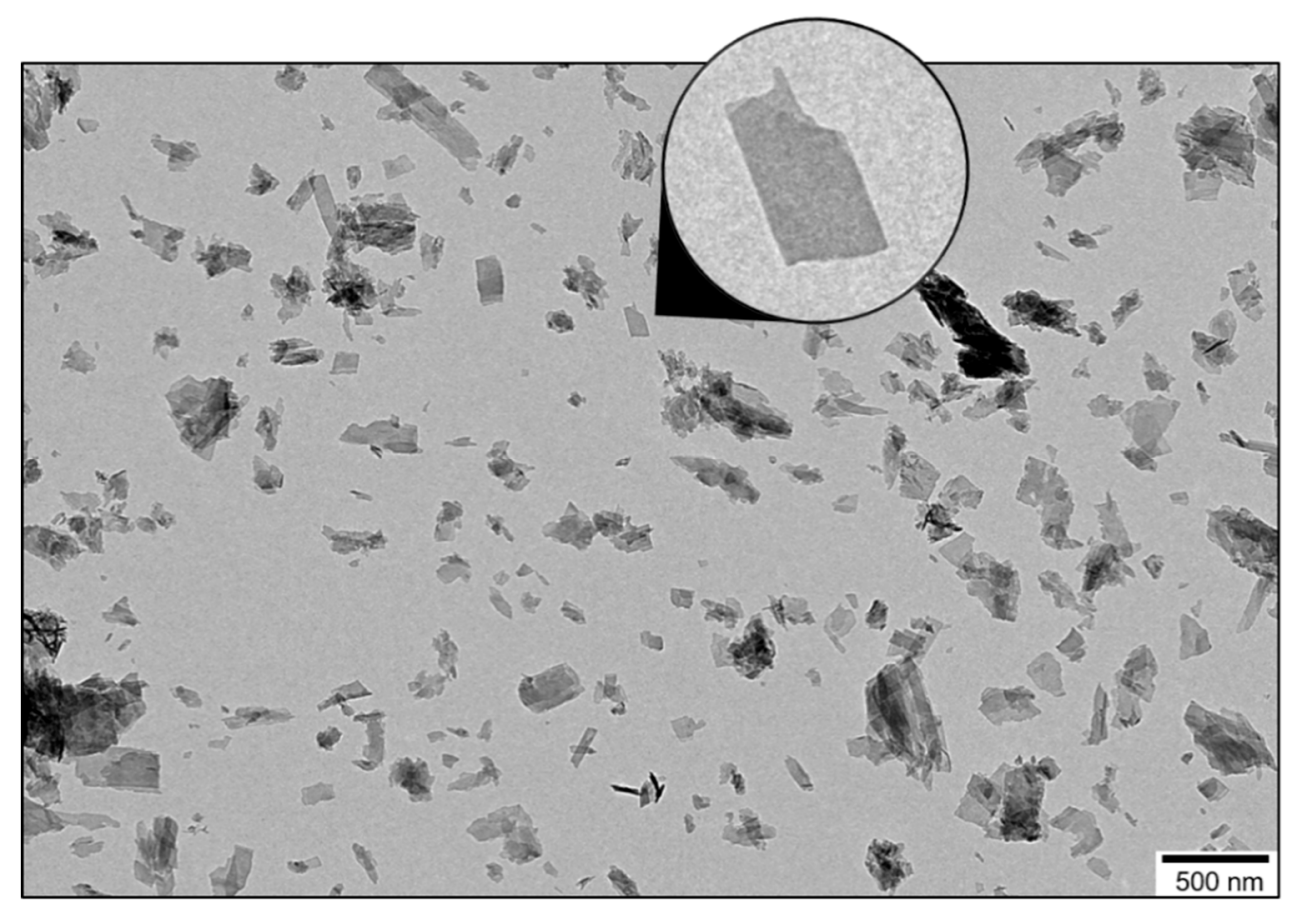

Figure 1. Morphological features of the bone-like hydroxyapatite particles. A representative transmission electron micrograph (TEM) of the synthetic Carbonated HydroxyApatite (CHA) particles. The inset shows a magnification of a single particle, which indicates that CHA is in the form of nanosized elongated platelets. 

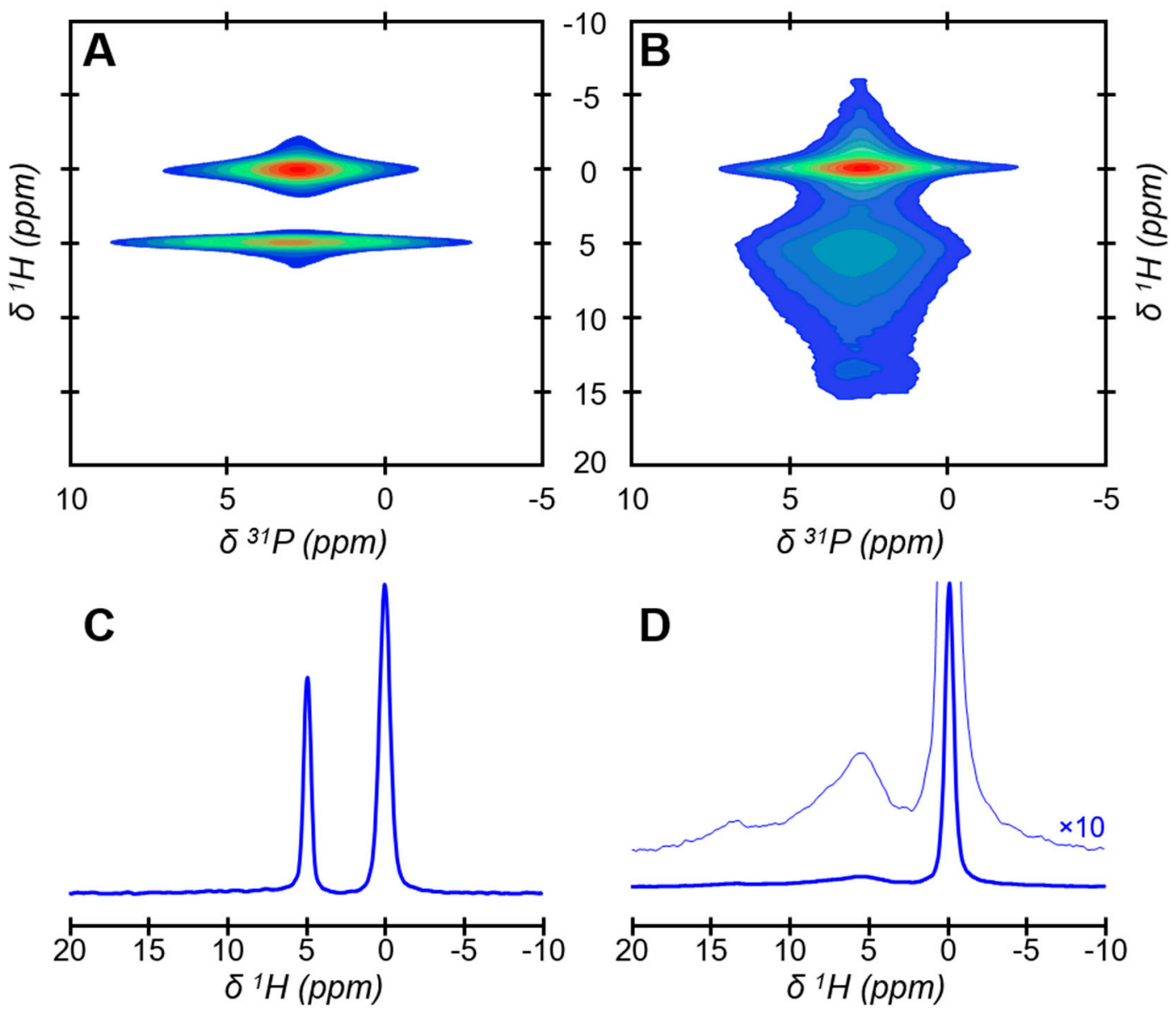

Figure 2. Spatial proximities between phosphorus and hydrogen species within the bone-like hydroxyapatite particles. Two-dimensional (2D) $\left\{{ }^{1} \mathrm{H}\right\}{ }^{31} \mathrm{P}$ Heteronuclear Correlation (HetCor) NMR spectra of the synthetic Carbonated HydroxyApatite (CHA) sample soaked in water (A) and in dry conditions (B). The signal intensity increases from blue to red. (C) Normalized one-dimensional (1D) ${ }^{1} \mathrm{H}$ projection of the vertical $\mathrm{F} 1$ dimension extracted from the $2 \mathrm{D}\left\{{ }^{1} \mathrm{H}\right\}{ }^{31} \mathrm{P}$ HetCor NMR spectrum of CHA soaked in water displayed in (A). (D) Normalized one-dimensional (1D) $1 \mathrm{H}$ projection of the vertical F1 dimension extracted from the $2 \mathrm{D}\{1 \mathrm{H}\} 31 \mathrm{P}$ HetCor NMR spectrum of CHA in dry conditions displayed in (B).

The behavior of CHA platelets in water was investigated by cryogenic TEM (Figure 3A,B). The platelets were here dispersed in deionized water at a high concentration, deposited on a copper grid, cryofixed in liquid ethane at $-174{ }^{\circ} \mathrm{C}$, and then observed in cryogenic conditions. This experiment was, therefore, achieved close to in vivo conditions in terms of hydration, since water bound to CHA platelets is here conserved and mimics the interstitial water [49] present in the collagen-apatite porosity (PCA) [50] of the bone extracellular matrix. A low-magnification cryogenic TEM micrograph of CHA suspended in water shows the presence of numerous dark zones that are rich in platelets (Figure 3A). A higher magnification micrograph demonstrates that they correspond to self-organized aggregates of platelets (Figure 3B). The platelets are here standing vertically and expose their smallest side faces, and, hence, their largest side faces are parallel to the electron beam. A close look at the regions between two adjacent platelets reveals the presence of narrow contrasted gaps (red arrows), which indicate that they are not in direct contact with each other. These gaps must be occupied by the large quantity of water molecules strongly bound to the amorphous surface layer that were evidenced by solid-state NMR spectroscopy. To confirm this, the cryofixed copper grid used here was collected, brought back to ambient temperature, and subsequently examined by TEM under vacuum. While dark zones rich in platelets are still observable at a low magnification (Figure 3C), the contrasted gaps between adjacent 
platelets are no longer observable at a higher magnification (red arrows; Figure 3D), which indicates that the dehydrated platelets are likely to be in direct contact with each other.
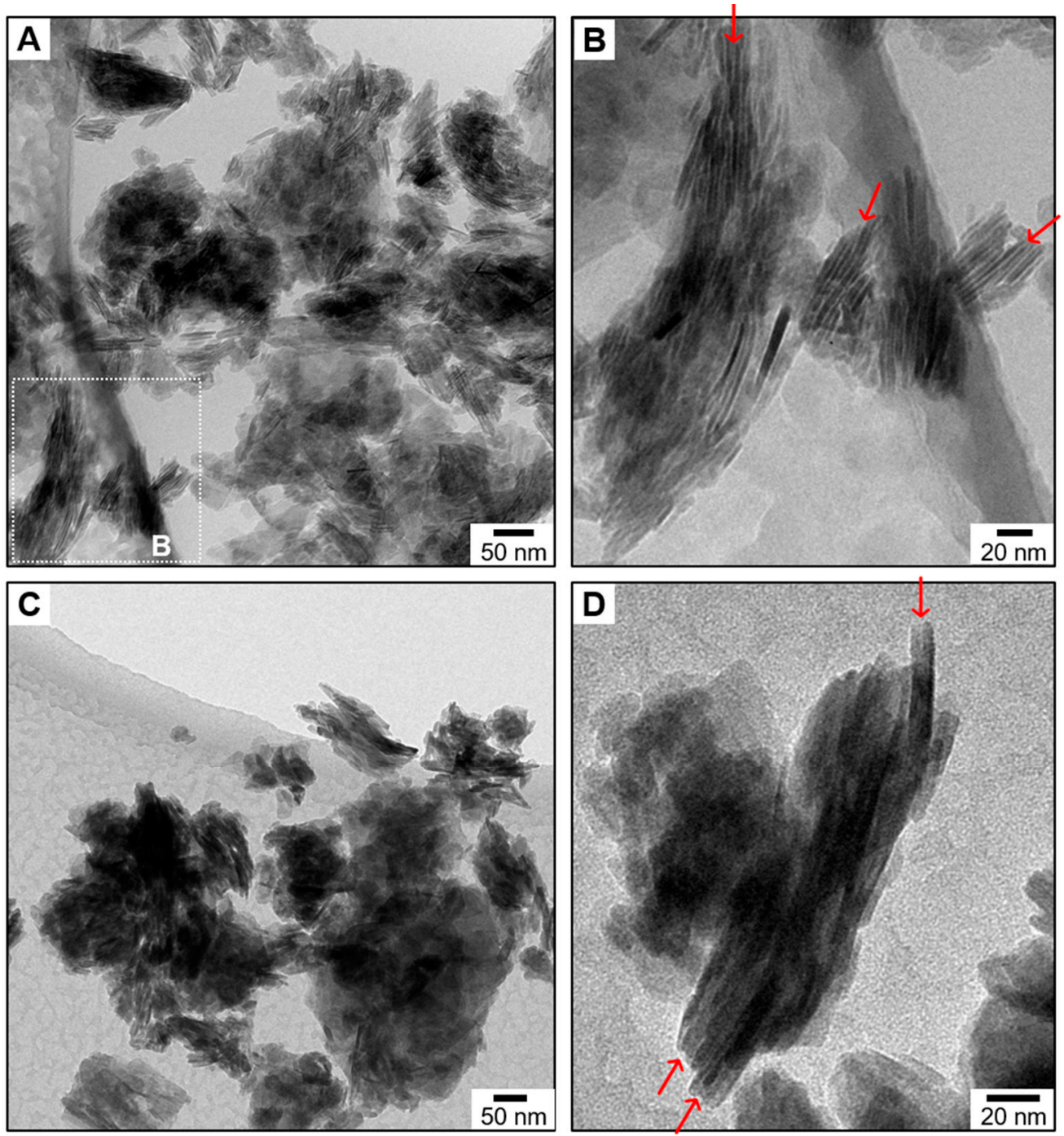

Figure 3. Behavior of the bone-like hydroxyapatite particles in water. (A,B) Representative cryogenic transmission electron micrographs (cryo-TEM) of the synthetic Carbonated HydroxyApatite (CHA) platelet-shaped particles dispersed in water. (B) shows a magnification of the rectangle region marked by the white dashed-line drawn in (A). The red arrows indicate the presence of narrow contrasted gaps in between CHA particles. Representative transmission electron micrographs (TEM) at low magnification (C) and at higher magnification (D) of the copper grid previously examined in cryogenic conditions in (A,B). The red arrows now indicate the absence of narrow contrasted gaps in between CHA particles.

Further cryogenic TEM observations show the presence of self-organized aggregates of CHA platelets in which numerous platelets are involved (Figure 4). Once again, the platelets are standing vertically and expose their smallest side faces. As bone mineral platelets in vivo, this organization occurs both perpendicular and parallel to their elongated direction. Perpendicular to their elongated direction, 16 platelets are here regularly stacked side-by-side in the form of a 40 -nm thick "deck of cards" in which their largest side faces are facing each other (Figure 4A). The narrow gaps, which are relatively electron-transparent and filled up with water in between platelets, are here highly visible both in the cryogenic TEM micrograph and in its corresponding contrast intensity profile (Figure 4B). A single platelet together with both sides of its hydration shell of bound water is here about 2.6-nm 
thick, which corresponds to the size of the bone mineral platelets since the majority of them are presumably less than 2-nm thick [6]. About 300-nm long elongated aggregates are also observable (Figure 4C), which are sometimes curved as seen at a higher magnification in Figure 4D,E. This, together with the fact that no single curved platelets were observed during our TEM observations in which they are sometimes seen edge-on (Figure S2), demonstrate that these curved and elongated aggregates involve a few platelets aligned with each other with slight misorientations. Interestingly, in a similar manner to that observed in bone, the junction between these aligned platelets is not discernible since no contrasted gaps are observable. Although an observational artefact due to a special orientation of the aggregates cannot be ruled out, this observation suggests that these platelets are interlocked together via a tight pairing of their basal faces. This phenomenon is surprising given the irregular shapes and dimensions of the CHA platelets; however, it correlates with the "mosaic composed of interlocking crystal tiles" proposed in bone [24].
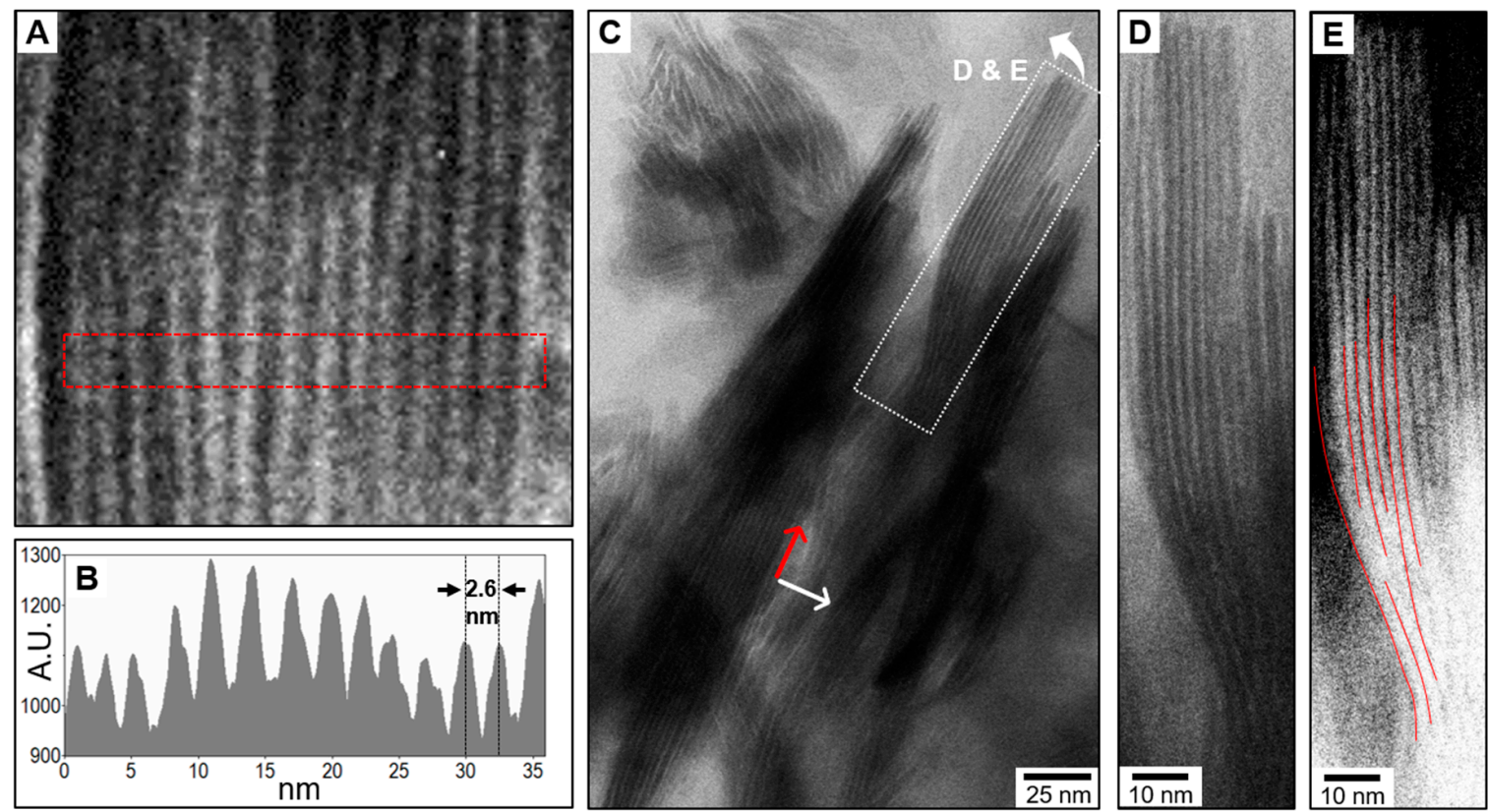

Figure 4. Self-organized aggregates of bone-like hydroxyapatite particles in water. (A,C,D,E) Cryogenic transmission electron micrographs (cryo-TEM) of the organized and oriented structures that the synthetic Carbonated HydroxyApatite (CHA) platelet-shaped particles form spontaneously in water. Shown in (A) is a self-organized aggregate in which the CHA platelets (seen edge-on) are regularly stacked side-by-side perpendicular to their elongated direction; displayed in (B) is its corresponding contrast intensity profile integrated over the rectangle region marked by the red dashed-line drawn in (A). Shown in (C) are self-organized aggregates in which numerous CHA platelets (seen edge-on) are not only aligned with each other but are also arranged side-by-side, respectively parallel (red arrow) and perpendicular (white arrow) to their elongated direction. (D) shows a magnification of the rectangle region marked by the white dashed-line drawn in (C), while (E) is a micrograph corresponding to the same region in which the colors, the contrast, and the brightness have been respectively inverted, enhanced, and lowered. The narrow gaps in between platelets appear here in black and are more visible; some of them have been covered by red lines to demonstrate the presence of gentle curvatures along the elongated direction of the platelets.

We also investigated the orientation of CHA platelets within the spherical polyparticle complexes that they form during their precipitation via a spherulitic growth mechanism. To this end, these relatively fragile spherulites were gently collected, dried at $37{ }^{\circ} \mathrm{C}$, encased in epoxy resin, and then sectioned to obtain electron-transparent thin sections for TEM analysis. A low-magnification TEM micrograph of a single spherulite (diameter, $\sim 3.3 \mu \mathrm{m}$ ) that was approximately cut in half is shown 
in Figure 5A, while Figure 5B-D correspond to higher magnification micrographs of different zones of the same spherulite, respectively the core, the zone next to the core, and the outer layer. The thin dark areas correspond to platelets standing vertically that expose their smallest side faces, while the more electron-transparent areas correspond both to platelets exposing their largest side faces and zones devoid of platelets. Overall, according to the observation of platelets seen edge-on (dark areas), the platelets are radially oriented in their elongated direction from the core of the spherulite to its outer layer. Restricted areas in which up to three or four platelets are locally co-oriented are observable; however, unlike our cryogenic TEM observations, no organized aggregates involving a significant number of platelets is here evidenced.
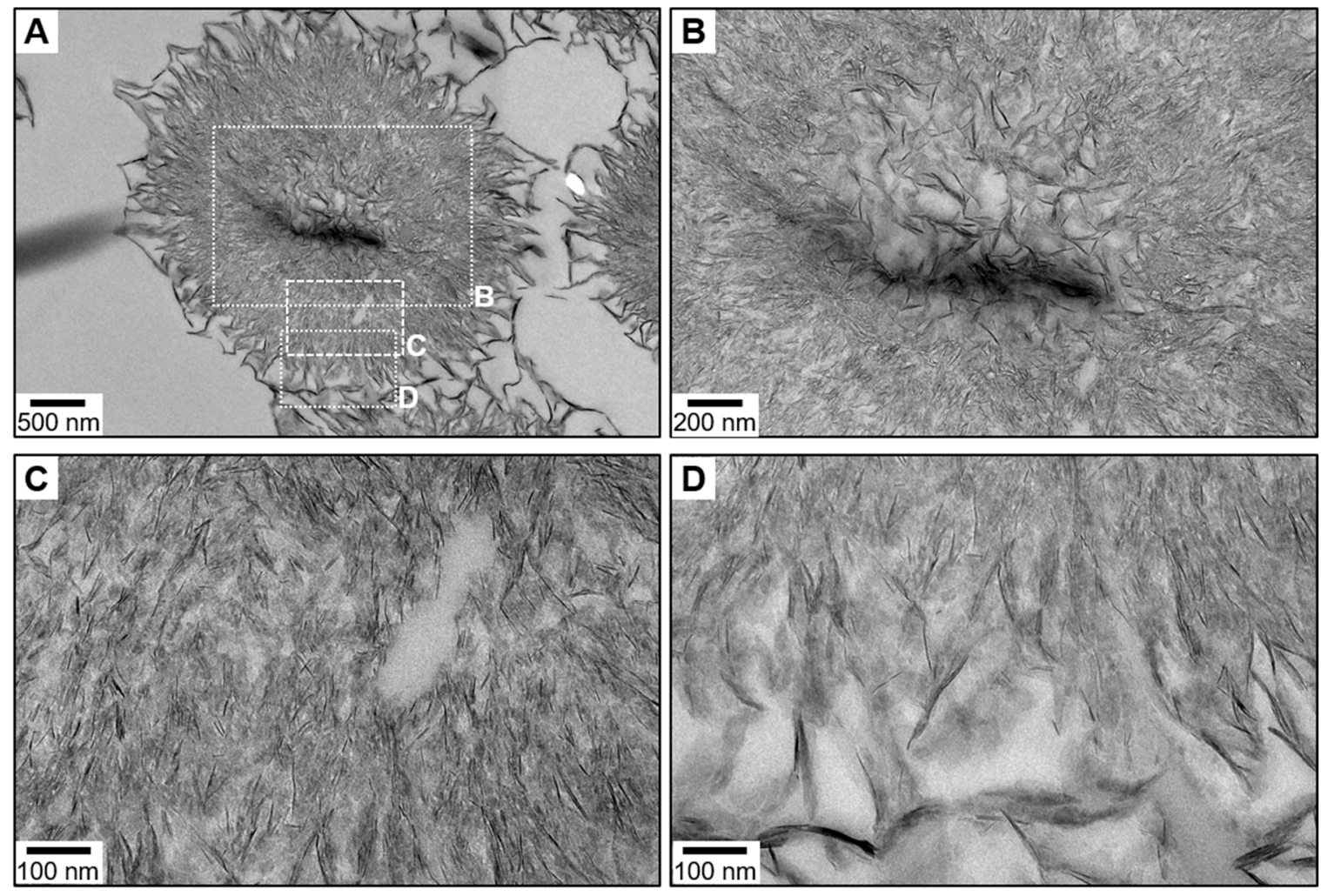

Figure 5. Orientation of the bone-like hydroxyapatite particles following their growth process. Shown are transmission electron micrographs (TEM) of a microtomed cross-section of Carbonated HydroxyApatite (CHA) spherulites. The region in (A) is a single spherulite that was approximately cut in half; (B) shows the core of the spherulite; (C) shows the zone next to the core shown in (B); while (D) shows the outer layer of the spherulite.

We further examined the importance of the platelet morphology to this self-assembly process. To this end, we prepared carbonated hydroxyapatite nanoparticles that are both in the form of needles and rods with different lengths, named CHA-needle/rod. They were prepared from the in-vivo-inspired conditions used for CHA, except that the reaction solution was continuously mechanically agitated during precipitation. The presence of a hydrophilic, amorphous surface layer that coats the CHA-needle/rod particles was confirmed in their $2 \mathrm{D}\left\{{ }^{1} \mathrm{H}\right\}{ }^{31} \mathrm{P}$ HetCor NMR spectrum (Figure S3). Hence, they must not only be coated by a rigid hydration shell of bound water when soaked in water, but possibly also have self-assembly properties. To assess this, a suspension of CHA-needle/rod in water was examined by cryogenic TEM (Figure 6). A low-magnification micrograph shows that CHA-needle/rod particles also tend to aggregate in water, since some dark zones rich in needles/rods are observable (Figure 6A). These aggregates seem to be largely composed of randomly oriented needles/rods, as seen in the micrograph shown in Figure S4, with rare exceptions, as shown in Figure 6B, in which a few needles/rods are locally co-oriented. Here as well, 
relatively electron-transparent narrow gaps (red arrows) filled up with water in between co-oriented needles/rods are observable by cryogenic TEM (Figure 6B), but not by TEM, in which the needles/rods seem to be in direct contact with each other (red arrows; Figure 6C-E).
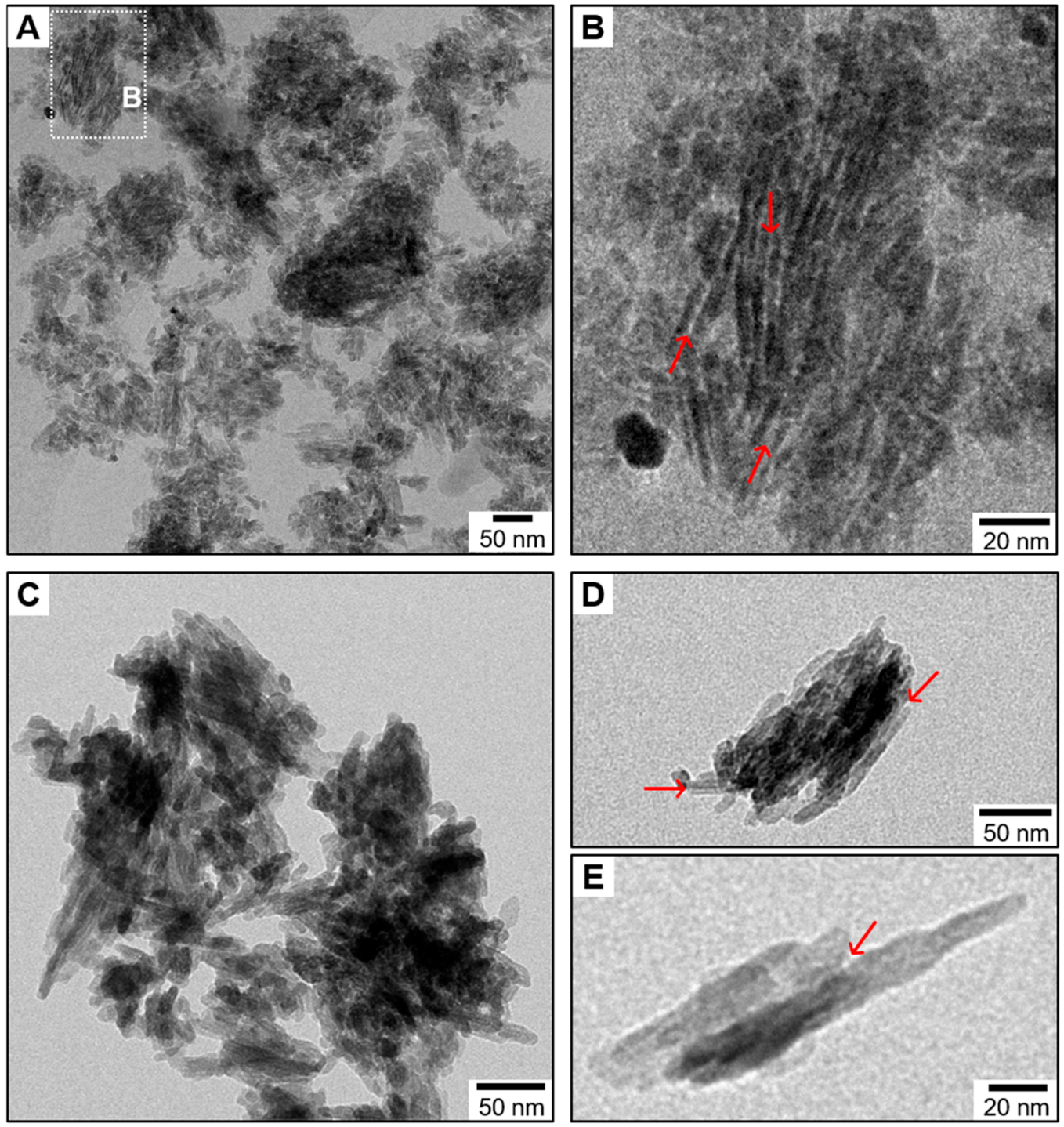

Figure 6. Behavior of the needle/rod-shaped carbonated hydroxyapatite particles in water and under vacuum. (A,B) Representative cryogenic transmission electron micrographs (cryo-TEM) of the synthetic needle/rod-shaped Carbonated HydroxyApatite (CHA-needle/rod) particles dispersed in water. (B) shows a magnification of the rectangle region marked by the white dashed-line drawn in (A). The red arrows indicate the presence of narrow contrasted gaps in between CHA-needle/rod particles. Representative transmission electron micrographs (TEM) at low magnification (C) and at higher magnification $(\mathbf{D}, \mathbf{E})$ of the copper grid previously examined in cryogenic conditions in $(\mathbf{A}, \mathbf{B})$. The red arrows now indicate the absence of narrow contrasted gaps in between CHA-needle/rod particles.

Last, since the hydrophilic, amorphous surface layer that coats bone and bone-like mineral platelets is rich in monohydrogen-phosphate ions, we inspected whether other $\mathrm{HPO}_{4}{ }^{2-}$-rich $\mathrm{CaP}$ minerals likewise possess strong hydrophilic properties. To do this, synthetic samples of monetite (DiCalcium Phosphate Anhydrous, DCPA) and brushite (DiCalcium Phosphate Dihydrate, DCPD) were studied in wet conditions using the $2 \mathrm{D}\left\{{ }^{1} \mathrm{H}\right\}{ }^{31} \mathrm{P}$ HetCor NMR experiment (Figure S5). Monetite is composed of $\mathrm{HPO}_{4}{ }^{2-}$ and $\mathrm{Ca}^{2+}$ ions $\left(\mathrm{CaHPO}_{4}\right)$, while brushite is composed of $\mathrm{HPO}_{4}{ }^{2-}$ and $\mathrm{Ca}^{2+}$ ions together with structural $\mathrm{H}_{2} \mathrm{O}$ molecules $\left(\mathrm{CaHPO}_{4} \cdot 2 \mathrm{H}_{2} \mathrm{O}\right)$. Again, a special rotor equipped with 
Teflon inserts was used so that the samples remained hydrated during the analysis. Given the very low intensity of the bound water signals at $\delta 1 \mathrm{H}=4.9 \mathrm{ppm}$ (red arrows), it turns out that neither monetite nor brushite are here capable of strongly adsorbing a large quantity of water molecules onto their surfaces.

\section{Discussion}

Atomic-scale spatial proximities between a large quantity of water molecules and the amorphous surface layer rich in $\mathrm{HPO}_{4}{ }^{2-}$ ions that coats bone-like hydroxyapatite platelets were evidenced. To achieve this, the 2D $\left\{{ }^{1} \mathrm{H}\right\}^{31} \mathrm{P}$ HetCor NMR experiment was performed in wet conditions. This solid-state NMR experiment is based on cross-polarization (CP) magnetization transfers from ${ }^{1} \mathrm{H}$ nuclei to nearby ${ }^{31} \mathrm{P}$ nuclei. Given the nature of the interactions involved in these CP magnetization transfers (i.e., heteronuclear $\left\{{ }^{1} \mathrm{H}\right\}^{31} \mathrm{P}$ dipolar couplings), this large quantity of water molecules is strongly bound to the amorphous surface layer. In other words, bone-like mineral platelets are coated by a rigid hydration shell of bound water when soaked in water. If we draw a parallel with bone mineral nanoparticles in vivo, we here confirm that their comparable hydration shell $[15,49,51]$ does not rely on the presence of bound hydrophilic bioorganic molecules but is due to the intrinsically hydrophilic nature of their amorphous surface layer, which is rich in $\mathrm{HPO}_{4}{ }^{2-}$ ions. In contrast, the surfaces of monetite $\left(\mathrm{CaHPO}_{4}\right)$ and brushite $\left(\mathrm{CaHPO}_{4} \cdot 2 \mathrm{H}_{2} \mathrm{O}\right)$ are not capable of strongly adsorbing a large quantity of water molecules in wet conditions according to our $2 \mathrm{D}\left\{{ }^{1} \mathrm{H}\right\}{ }^{31} \mathrm{P}$ HetCor NMR experiments. Note that the intensity of the bound water signals in the spectra of monetite and brushite is not directly comparable with the intensity of the bound water signal in the spectrum of CHA, since the former are here in the form microsized crystals with relatively low specific surface areas. However, the apparent lack of hydrophilic properties for monetite and brushite nevertheless suggests that the hydrophilic properties of the amorphous surface layer are due to its specific chemical structure, which is close to ACP, rather than its chemical composition. In other words, dibasic calcium phosphate chemical environments are here not hydrophilic when they are in a crystalline form, whereas they are highly hydrophilic at the surface of bone-like hydroxyapatite particles where they are in the form of amorphous calcium phosphate. In this direction, the fact that the entire signal of the $\mathrm{HPO}_{4}{ }^{2-}$ ions from the amorphous surface layer is not observed in wet conditions shows that their acidic protons undergo fast chemical exchanges with the protons from the surrounding water molecules. Interestingly, we also revealed that the chemical structure of the amorphous surface layer has been altered following hydration, since its ${ }^{31} \mathrm{P}$ chemical environments have been modified. Since a simple physisorption process, which is usually reversible, and which involves relatively weak physical forces, should not affect the chemical structure of the surface layer, an additional scenario must be considered here. The most likely scenario, which supports both the chemical exchanges as well as the structural alteration, is that water molecules penetrate into the amorphous surface layer. Our results, therefore, suggest that, in wet conditions, a large quantity of water molecules is not only strongly bound to but is also trapped within the amorphous surface layer. Since the arrangement of ions/molecules within the amorphous surface layer is sometimes seen as a reminiscence of the state in which the ions/molecules were prior to their incorporation into the solid phase [52], we can assume that these additional trapped water molecules form hydration spheres around the surface ions. Hence, the trapped water molecules might be part of the first hydration sphere of the surface ions, while the bound water molecules might be part of the second or third hydration sphere of the surface ions. In this configuration, we can imagine that these hydrated ions are loosely bound to the particles' surface, which would explain why they are easily and reversibly exchangeable by other ions that are dissolved in the surrounding aqueous solution [53-55].

Our cryogenic TEM observations show that bone-like hydroxyapatite platelets self-assemble in water. This was also verified in our TEM observations of a spherulite, since they demonstrated that this self-assembly ability is not a remnant from their growth process. When dispersed in water, numerous bone-like hydroxyapatite platelets form organized and oriented structures similar to those 
observed in bone as schematized in Figure 7. Perpendicular to their elongated direction, up to 16 platelets were here shown stacked together in the form of a 40 -nm thick "deck of cards", in which their largest side faces are facing each other. Parallel to their elongated direction, it was demonstrated that a few platelets are here aligned with each other over a distance that can reach up to $300 \mathrm{~nm}$. In comparison, $300 \mathrm{~nm}$ is about the size of a triple helix collagen molecule, while $40 \mathrm{~nm}$ is equivalent to about half the thickness of a bone collagen fibril. It was also shown here that mineral platelets dispersed in water sometimes form curved structures that were likewise observed in bone, and described as lacy patterns of mineral structures [21] in which "the platelet-shaped aggregates often show a gentle twist along their longitudinal axis, resembling the shape of a fan blade" [5]. When stacked perpendicularly to their elongated direction, it is clear that the mineral platelets are not in direct contact with each other, since narrow gaps in between them were evidenced. Such narrow gaps in between mineral nanoparticles were also observed both in bone [5,24,56] and in dentin [26]. The present study along with previous studies $[15,49,51]$ suggest that they are most likely to be occupied by the rigid hydration shell of bound water. In such a configuration, the hydration shell not only drives the mineral-mineral interactions but also drives the mineral-organic interactions, which emphasizes the need to study the macroscopic physical properties of bone from fresh and fully hydrated bone tissue samples. Regarding the mineral-mineral interactions, the main question here is what types of attractive forces hold the mineral platelets together in water? We showed in a previous study that the bone-like hydroxyapatite platelets used here (CHA) have a very low electric potential at the slipping plane ( $\zeta$-potential) [15]. We, therefore, assume that the mineral platelets are held together by cooperative van der Waals forces and hydrogen bonds between water molecules engaged in the respective rigid hydration shell of adjacent platelets. However, due to the difficulty of obtaining a well-dispersed suspension of mineral platelets in water because of their self-assembly ability, together with the surface ion exchanges and the phenomenon of maturation during which the amorphous surface layer progressively transforms into more stable apatitic environments [57], the determination of their surface charge is challenging. Accordingly, we cannot rule out the possibility of a scenario similar to that of the layered structures of clay mineral platelets whose surface charges are balanced by ions intercalated in the interlayer gaps together with water molecules. Interestingly, despite the fact that they are also coated by a hydrophilic surface layer, we showed that needle/rod-shaped hydroxyapatite particles do not form self-organized aggregates involving a significant number of particles in water. This suggests that mature bone mineral nanoparticles adopt this typical platelet-like morphology to maximize the shared surface between adjacent nanoparticles so that the cooperative van der Waals forces and hydrogen bonds mediated by the rigid hydration shell provide enough attraction to hold the nanoparticles together. This mechanism supports the fact that the largest side faces of the platelets tend to face each other; however, how the platelets are also aligned with each other needs to be determined. In this direction, we showed that the platelets aligned with each other seem to be interlocked together via a tight pairing of their basal faces. To explain this, two different mechanisms can be considered. First, the amorphous surface layer could initially link the platelets together in an oriented manner, and could subsequently crystalize into hydroxyapatite [58]. Second, this alignment could occur through a mechanism of oriented attachment [59], while the curved structures may be formed by an imperfect oriented attachment [60]. This second scenario implies that the amorphous surface layer is not developed on the platelets' basal faces so that the apatite lattice from adjacent platelets can match. The prevalence of one or the other mechanism should be clarified, and, hence, high-resolution TEM and/or in situ liquid cell TEM observations need to be made in the future. 

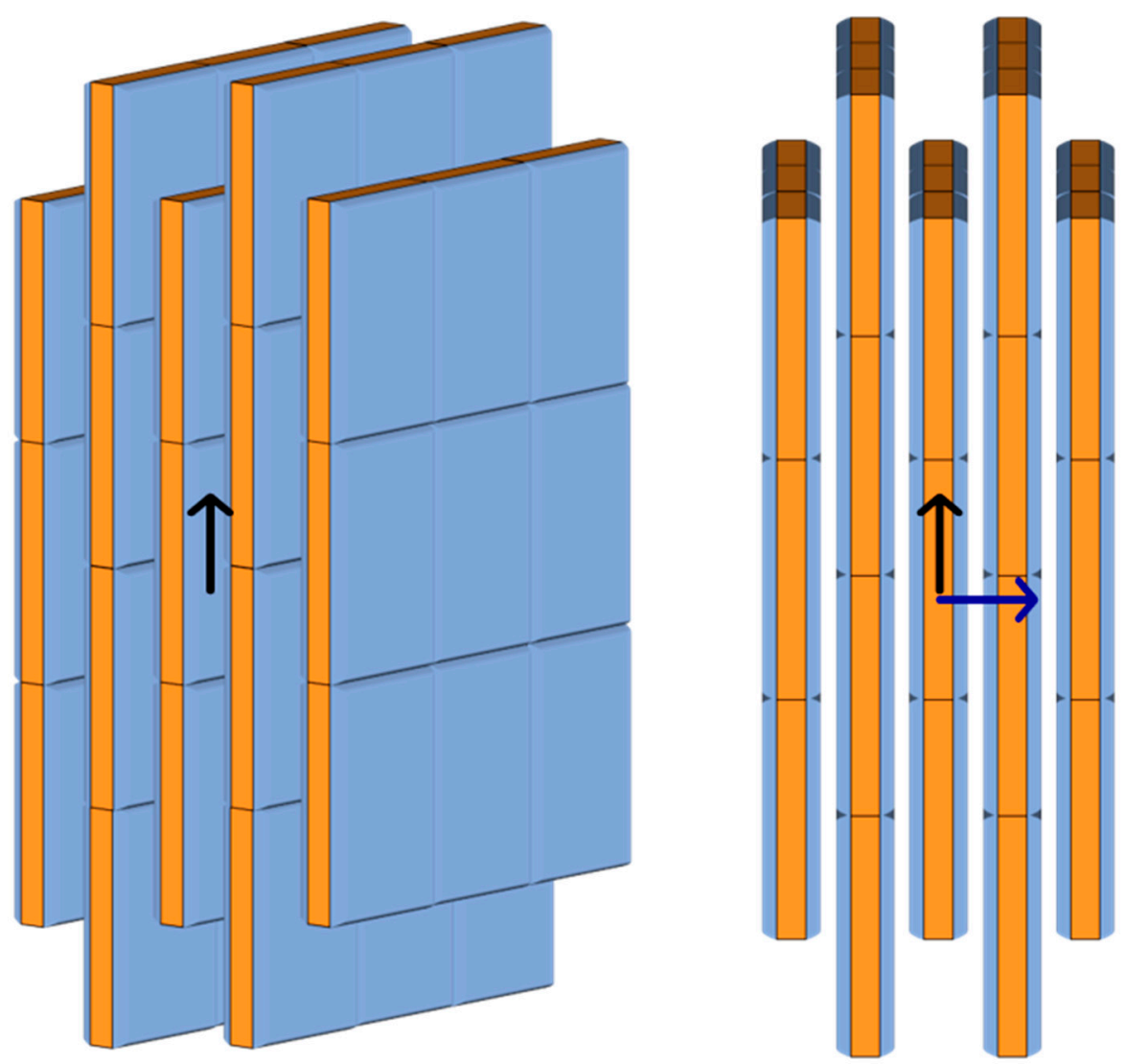

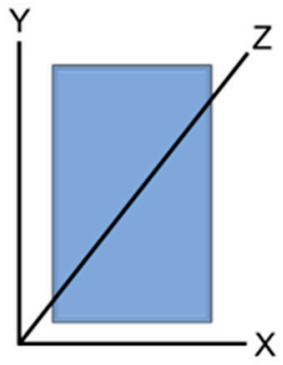

(i)

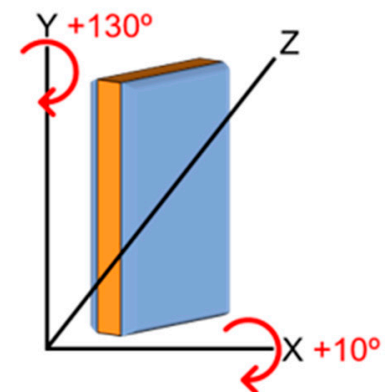

(ii)

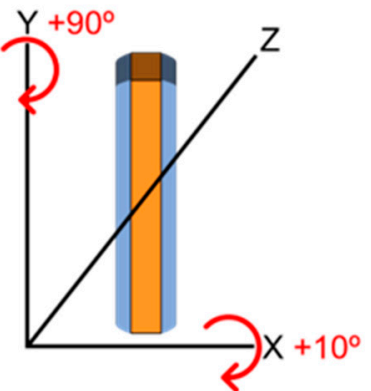

(iii)

Figure 7. A simplified schematic drawing of the local organization of bone mineral platelets in vivo. Here is schematized the presumed local organization of mature bone mineral nanoparticles throughout the bone extracellular matrix in vivo. It was deducted according to the self-organized structures that bone-like platelet-shaped hydroxyapatite particles form spontaneously in water. This organization is here depicted in a simplified manner in which the mineral platelets have similar shapes and dimensions, together with an identical orientation. A model with a staggered arrangement of mineral platelets was considered according to the work of Ingomar Jäger and Peter Fratzl [61]. The largest side faces of the platelets are filled in blue (a single platelet is shown face-on in (i)), while their smallest side faces together with their basal faces are filled in orange (a single platelet is shown tilted and edge-on in (ii,iii), respectively). The platelets are not only aligned with each other but are also arranged side-by-side, respectively parallel (black arrow) and perpendicular (blue arrow) to their elongated direction. The largest side faces of the platelets are, therefore, facing each other but are separated by water-filled gaps, and the platelets are also interlocked together via a tight pairing of their basal faces. The assumption was made here that the platelets also assemble at the level of their smallest side faces to form "a mosaic composed of interlocking crystal tiles" [22]; however, our two-dimensional imaging data could not confirm this. 


\section{Conclusions}

Here, we not only investigated the mineral-water interactions, but also examined how interfacial water can drive the mineral aggregation and organization process in bone. To this end, we used bone-like platelet-shaped hydroxyapatite particles as a proxy for mature bone mineral particles. First, our results suggest that a large quantity of water molecules must not only be strongly bound to, but must also be trapped within, the amorphous surface layer that coats bone mineral nanoparticles. The strongly bound water molecules are very likely to form a rigid hydration shell around the bone mineral platelets such that their largest side faces are not in direct contact with each other. As for trapped water molecules, they presumably form hydration spheres around the surface ions in a configuration that is reminiscent of that of the ions prior to their incorporation into the solid phase [52]. These results give rise to the question of whether this incorporation of water molecules into the surface could be the origin of the amorphisation of the outer surface of bone mineral nanoparticles. In addition, our results also suggest that platelet-shaped, mature bone mineral particles are likely to aggregate and self-assemble into organized mineral structures without recourse to bioorganic molecules (non-collagenous proteins, collagen, or citrate). This self-assembly ability is particularly meaningful for the mineral that is external to collagen. It could enable the bone mineral platelets to conserve their organization throughout the winding volume that exists between disordered collagen fibrils and fibers such that the mineral matrix can form a "continuous cross-fibrillar phase" [5]. Further, the mechanisms by which these platelets are held together within those organized mineral structures have been discussed. Perpendicularly to their elongated direction, there is evidence that water molecules from the rigid hydration shells of adjacent mineral platelets drive the mineral-mineral interactions. We assume that cohesive forces (cooperative van der Waals forces and hydrogen bonds) between those water molecules are the main attractive forces that hold the largest side faces of the platelets together. According to our observations from needle/rod-shaped hydroxyapatite nanoparticles, we also proposed that this typical platelet-like morphology maximizes the shared surface between adjacent bone mineral particles so that these cohesive forces are strong enough to hold the particles together. Parallel to their elongated direction, it is unclear how the basal faces of the platelets seem to be interlocked in a way such that the mineral platelets are aligned with each other. We assume that two different options are possible: the adjacent platelets could initially be connected through their amorphous surface layer that subsequently crystalizes into hydroxyapatite [58], or this could also result from repeated oriented attachment events.

The results presented here and elsewhere [15,62] provide key information for further discussions about bone biomineralization, bone poroelasticity, and even the mechanical properties of hydrated bone. They may also form the foundation for the development of the next generation (4th generation) of alloplasts for bone regeneration, which aspires to replicate the chemical, structural, and physical properties of a natural bone tissue. It is also certain that the methodology used here could be very advantageous for investigating the interactions of water with other types of minerals, including phosphates and carbonates. This is especially the case for biological dentine hydroxyapatite [63], biological coral [64] and nacre [65] aragonites, and sedimentary aragonite (from microbialites) [66], for which an analogous amorphous surface layer around a crystalline particle core was also evidenced.

Supplementary Materials: The following are available online at http:/ /www.mdpi.com/2076-3263/8/12/466/s1, Figure S1: Individual ${ }^{31} \mathrm{P}$ signals of the crystalline nanoparticle core and the amorphous surface layer within bone-like hydroxyapatite particles, together with their evolution from dry to wet conditions. Shown are the normalized one-dimensional (1D) individual ${ }^{31} \mathrm{P}$ NMR signals of the crystalline nanoparticle core (left) and the amorphous surface layer (right) of the synthetic Carbonated HydroxyApatite (CHA) particles in dry conditions (bottom) and soaked in water (top). These individual ${ }^{31} \mathrm{P}$ NMR signals were extracted from the two-dimensional (2D) $\left\{{ }^{1} \mathrm{H}\right\}^{31} \mathrm{P}$ Heteronuclear Correlation (HetCor) NMR spectra that are shown here. The sums of the F2 slices taken at the $\mathrm{OH}^{-}$ions position (from $\delta^{1} \mathrm{H}=-2$ to $2 \mathrm{ppm}$ ) in $\mathrm{F} 1$ have been used to generate the individual ${ }^{31} \mathrm{P}$ signals of the crystalline nanoparticle core both in dry and wet conditions. The sums of the F2 slices taken at the bound water molecules position (from $\delta^{1} \mathrm{H}=3$ to $7 \mathrm{ppm}$ ) or the residual structural water molecules together with $\mathrm{HPO}_{4}{ }^{2-}$ ions position (from $\delta^{1} \mathrm{H}=3$ to $17 \mathrm{ppm}$ ) in $\mathrm{F} 1$ have been used to generate the individual 
${ }^{31} \mathrm{P}$ signals of the amorphous surface layer, respectively in wet and dry conditions. Figure S2: Observations of bone-like platelet-shaped hydroxyapatite particles seen edge-on. Transmission electron micrograph (TEM) of the synthetic Carbonated HydroxyApatite (CHA) particles. Some of them are here standing vertically such that their smallest side faces are exposed while their largest side faces are parallel to the electron beam. Figure S3: Spatial proximities between phosphorus and hydrogen species within the needle/rod-shaped carbonated hydroxyapatite particles. (A) Two-dimensional (2D) $\left\{{ }^{1} \mathrm{H}\right\}{ }^{31} \mathrm{P}$ Heteronuclear Correlation (HetCor) NMR spectrum of the synthetic needle/rod-shaped Carbonated HydroxyApatite (CHA-needle/rod) sample. Signal intensity increases from blue to red. (B) One-dimensional (1D) ${ }^{1} \mathrm{H}$ projection of the vertical F1 dimension extracted from the 2D $\left\{{ }^{1} \mathrm{H}\right\}^{31} \mathrm{P}$ HetCor NMR spectrum displayed in (A). Figure S4: Behavior of the needle/rod-shaped carbonated hydroxyapatite particles in water. Shown is a representative cryogenic transmission electron micrograph (cryo-TEM) of the synthetic needle/rod-shaped Carbonated HydroxyApatite (CHA-needle/rod) particles dispersed in water. Figure S5: Spatial proximities between phosphorus and hydrogen species within monetite and brushite. Two-dimensional (2D) $\left\{{ }^{1} \mathrm{H}\right\}{ }^{31} \mathrm{P}$ Heteronuclear Correlation (HetCor) NMR spectra of synthetic monetite (A) and brushite (C) samples soaked in water ( $\mathrm{pH} 4$ ). Signal intensity increases from blue to red. Normalized one-dimensional (1D) ${ }^{1} \mathrm{H}$ projections of the vertical F1 dimensions extracted from the $2 \mathrm{D}\left\{{ }^{1} \mathrm{H}\right\}{ }^{31} \mathrm{P}$ HetCor NMR spectra of monetite (B) and brushite (D). For monetite, the spatial proximities among the various ${ }^{1} \mathrm{H}$ and ${ }^{31} \mathrm{P}$ nuclei in the $\mathrm{HPO}_{4}{ }^{2-}$ ions are detected as two correlation peaks observable at $\delta^{31} \mathrm{P}=-0.2$ and $-1.4 \mathrm{ppm}$ in the F2 $\left({ }^{31} \mathrm{P}\right)$ dimension, which are both associated with two correlation peaks observable at $\delta^{1} \mathrm{H}=13.3$ and $16.1 \mathrm{ppm}$ in the $\mathrm{F} 1\left({ }^{1} \mathrm{H}\right)$ dimension. For brushite, the spatial proximities among the various ${ }^{1} \mathrm{H}$ and ${ }^{31} \mathrm{P}$ nuclei in the $\mathrm{HPO}_{4}{ }^{2-}$ ions are detected as a single correlation peak observable at $\delta^{31} \mathrm{P}=1.4 \mathrm{ppm}$ in the $\mathrm{F} 2\left({ }^{31} \mathrm{P}\right)$ dimension and in the range of $\delta^{1} \mathrm{H}=8-15 \mathrm{ppm}$ in the F1 $\left({ }^{1} \mathrm{H}\right)$ dimension. In addition, the structural water molecules present in brushite are detected as a broad correlation peak observable at $\delta^{31} \mathrm{P}=1.4 \mathrm{ppm}$ in the $\mathrm{F} 2\left({ }^{31} \mathrm{P}\right)$ dimension and centered at around $\delta^{1} \mathrm{H}=5 \mathrm{ppm}$ in the $\mathrm{F} 1\left({ }^{1} \mathrm{H}\right)$ dimension. Last, the red arrows indicate the presence of tiny signals of bound water which are not observable is dry conditions.

Author Contributions: For research articles with several authors, a short paragraph specifying their individual contributions must be provided. The following statements should be used "conceptualization, S.V.E., N.N. and T.A.; methodology, S.V.E., N.N. and T.A.; software, S.V.E. and G.L.; validation, S.V.E., N.N. and T.A.; formal analysis, S.V.E., N.N. and T.A.; investigation, S.V.E., T.-H.-C.C.-C., C.P., B.H. and G.P.-A.; resources, F.B.; data curation, S.V.E.; writing - original draft preparation, S.V.E.; writing—review and editing, S.V.E.; visualization, S.V.E.; supervision, F.B., N.N., and T.A.; project administration, F.B.; funding acquisition, F.B.".

Funding: This research received no external funding.

Acknowledgments: We thank P. Le Griel for technical support. We thank the laboratory of excellence (Labex) Matisse for supporting part of this research work.

Conflicts of Interest: The authors declare no conflict of interest.

\section{References}

1. Nudelman, F.; Lausch, A.J.; Sommerdijk, N.A.J.M.; Sone, E.D. In vitro models of collagen biomineralization. J. Struct. Biol. 2013, 183, 258-269. [CrossRef] [PubMed]

2. Liu, Y.; Luo, D.; Wang, T. Hierarchical Structures of Bone and Bioinspired Bone Tissue Engineering. Small 2016, 12, 4611-4632. [CrossRef]

3. Weiner, S.; Traub, W. Organization of hydroxyapatite crystals within collagen fibrils. FEBS Lett. 1986, 206, 262-266. [CrossRef]

4. Alexander, B.; Daulton, T.L.; Genin, G.M.; Lipner, J.; Pasteris, J.D.; Wopenka, B.; Thomopoulos, S. The nanometre-scale physiology of bone: Steric modelling and scanning transmission electron microscopy of collagen-mineral structure. J. R. Soc. Interface 2012, 9, 1774-1786. [CrossRef] [PubMed]

5. Reznikov, N.; Bilton, M.; Lari, L.; Stevens, M.M.; Kröger, R. Fractal-like hierarchical organization of bone begins at the nanoscale. Science 2018, 360, eaao2189. [CrossRef] [PubMed]

6. Eppell, S.J.; Tong, W.; Katz, J.L.; Kuhn, L.; Glimcher, M.J. Shape and size of isolated bone mineralites measured using atomic force microscopy. J. Orthop. Res. 2001, 19, 1027-1034. [CrossRef]

7. Kim, H.-M.; Rey, C.; Glimcher, M.J. Isolation of calcium-phosphate crystals of bone by non-aqueous methods at low temperature. J. Bone Miner. Res. 1995, 10, 1589-1601. [CrossRef] [PubMed]

8. Bocciarelli, D.S. Morphology of crystallites in bone. Calcif. Tissue Res. 1970, 5, 261-269. [CrossRef] [PubMed]

9. Cho, G.; Wu, Y.; Ackerman, J.L. Detection of Hydroxyl Ions in Bone Mineral by Solid-State NMR Spectroscopy. Science 2003, 300, 1123-1127. [CrossRef] [PubMed]

10. Loong, C.K.; Rey, C.; Kuhn, L.T.; Combes, C.; Wu, Y.; Chen, S.; Glimcher, M.J. Evidence of hydroxyl-ion deficiency in bone apatites: An inelastic neutron-scattering study. Bone 2000, 26, 599-602. [CrossRef] 
11. Legros, R.; Balmain, N.; Bonel, G. Age-related changes in mineral of rat and bovine cortical bone. Calcif. Tissue Int. 1987, 41, 137-144. [CrossRef] [PubMed]

12. Neuman, W.F.; Neuman, M.W.; Main, E.R.; O'leary, J.; Smith, F.A. The surface chemistry of bone. II. Fluoride deposition. J. Biol. Chem. 1950, 187, 655-661. [PubMed]

13. De Jong, W.F. La Substance Minérale Dans les Os. Recl. Trav. Chim. Pays-Bas. 1926, 45, 445-448. [CrossRef]

14. Elliott, J. Structure and Chemistry of the Apatites and Other Calcium Orthophosphates; Elsevier Science: Amsterdam, The Netherlands, 1994.

15. Wang, Y.; Von Euw, S.; Fernandes, F.M.; Cassaignon, S.; Selmane, M.; Laurent, G.; Pehau-Arnaudet, G.; Coelho, C.; Bonhomme-Coury, L.; Giraud-Guille, M.-M.; et al. Water-mediated structuring of bone apatite. Nat. Mater. 2013, 12, 1144-1153. [CrossRef] [PubMed]

16. Wilson, E.E.; Awonusi, A.; Morris, M.D.; Kohn, D.H.; Tecklenburg, M.M.J.; Beck, L.W. Three Structural Roles for Water in Bone Observed by Solid-State NMR. Biophys. J. 2006, 90, 3722-3731. [CrossRef] [PubMed]

17. Von Euw, S. Bone Biomineralization: From the Structural Characterization of the Mineral to Its 3D Organization. Ph.D. Thesis, UPMC, Paris, France, 2014.

18. Von Euw, S.; Ajili, W.; Chan-Chang, T.-H.-C.; Delices, A.; Laurent, G.; Babonneau, F.; Nassif, N.; Azaïs, T. Amorphous surface layer versus transient amorphous precursor phase in bone-A case study investigated by solid-state NMR spectroscopy. Acta Biomater. 2017, 59, 351-360. [CrossRef] [PubMed]

19. Jäger, C.; Welzel, T.; Meyer-Zaika, W.; Epple, M. A solid-state NMR investigation of the structure of nanocrystalline hydroxyapatite. Magn. Reson. Chem. 2006, 44, 573-580. [CrossRef]

20. Wang, Y.; Von Euw, S.; Laurent, G.; Crevant, C.; Bonhomme-Coury, L.; Giraud-Guille, M.-M.; Babonneau, F.; Nassif, N.; Azaïs, T. Impact of collagen confinement vs. ionic substitutions on the local disorder in bone and biomimetic apatites. Mater. Horiz. 2014, 1, 224-231. [CrossRef]

21. McNally, E.A.; Schwarcz, H.P.; Botton, G.A.; Arsenault, A.L. A Model for the Ultrastructure of Bone Based on Electron Microscopy of Ion-Milled Sections. PLoS ONE 2012, 7, e29258. [CrossRef]

22. McNally, E.; Nan, F.; Botton, G.A.; Schwarcz, H.P. Scanning transmission electron microscopic tomography of cortical bone using Z-contrast imaging. Micron 2013, 49, 46-53. [CrossRef]

23. Weiner, S.; Arad, T.; Traub, W. Crystal organization in rat bone lamellae. FEBS Lett. 1991, 285, 49-54. [CrossRef]

24. Schwarcz, H.P.; McNally, E.A.; Botton, G.A. Dark-field transmission electron microscopy of cortical bone reveals details of extrafibrillar crystals. J. Struct. Biol. 2014, 188, 240-248. [CrossRef] [PubMed]

25. Olszta, M.J.; Cheng, X.; Jee, S.S.; Kumar, R.; Kim, Y.-Y.; Kaufman, M.J.; Douglas, E.P.; Gower, L.B. Bone structure and formation: A new perspective. Mater. Sci. Eng. R Rep. 2007, 58, 77-116. [CrossRef]

26. Beniash, E. Biominerals-hierarchical nanocomposites: The example of bone: Biominerals-hierarchical nanocomposites. Wiley Interdiscip. Rev. Nanomed. Nanobiotechnol. 2011, 3, 47-69. [CrossRef] [PubMed]

27. Burger, C.; Zhou, H.; Wang, H.; Sics, I.; Hsiao, B.S.; Chu, B.; Graham, L.; Glimcher, M.J. Lateral Packing of Mineral Crystals in Bone Collagen Fibrils. Biophys. J. 2008, 95, 1985-1992. [CrossRef] [PubMed]

28. George, A.; Veis, A. Phosphorylated Proteins and Control over Apatite Nucleation, Crystal Growth, and Inhibition. Chem. Rev. 2008, 108, 4670-4693. [CrossRef] [PubMed]

29. He, G.; Dahl, T.; Veis, A.; George, A. Nucleation of apatite crystals in vitro by self-assembled dentin matrix protein 1. Nat. Mater. 2003, 2, 552-558. [CrossRef]

30. Beniash, E.; Deshpande, A.S.; Fang, P.A.; Lieb, N.S.; Zhang, X.; Sfeir, C.S. Possible role of DMP1 in dentin mineralization. J. Struct. Biol. 2011, 174, 100-106. [CrossRef]

31. Deshpande, A.S.; Fang, P.-A.; Zhang, X.; Jayaraman, T.; Sfeir, C.; Beniash, E. Primary Structure and Phosphorylation of Dentin Matrix Protein 1 (DMP1) and Dentin Phosphophoryn (DPP) Uniquely Determine Their Role in Biomineralization. Biomacromolecules 2011, 12, 2933-2945. [CrossRef] [PubMed]

32. Nudelman, F.; Pieterse, K.; George, A.; Bomans, P.H.H.; Friedrich, H.; Brylka, L.J.; Hilbers, P.A.J.; de With, G.; Sommerdijk, N.A.J.M. The role of collagen in bone apatite formation in the presence of hydroxyapatite nucleation inhibitors. Nat. Mater. 2010, 9, 1004-1009. [CrossRef]

33. Liu, Y.; Kim, Y.-K.; Dai, L.; Li, N.; Khan, S.O.; Pashley, D.H.; Tay, F.R. Hierarchical and non-hierarchical mineralisation of collagen. Biomaterials 2011, 32, 1291-1300. [CrossRef] [PubMed]

34. Deshpande, A.S.; Beniash, E. Bioinspired Synthesis of Mineralized Collagen Fibrils. Cryst. Growth Des. 2008, 8, 3084-3090. [CrossRef] [PubMed] 
35. Dai, L.; Qi, Y.-P.; Niu, L.-N.; Liu, Y.; Pucci, C.R.; Looney, S.W.; Ling, J.-Q.; Pashley, D.H.; Tay, F.R. Inorganic-Organic Nanocomposite Assembly Using Collagen as a Template and Sodium Tripolyphosphate as a Biomimetic Analog of Matrix Phosphoprotein. Cryst. Growth Des. 2011, 11, 3504-3511. [CrossRef] [PubMed]

36. Niu, L.; Jee, S.E.; Jiao, K.; Tonggu, L.; Li, M.; Wang, L.; Yang, Y.; Bian, J.; Breschi, L.; Jang, S.S.; et al. Collagen intrafibrillar mineralization as a result of the balance between osmotic equilibrium and electroneutrality. Nat. Mater. 2017, 16, 370-378. [CrossRef] [PubMed]

37. Rhee, S.-H.; Suetsugu, Y.; Tanaka, J. Biomimetic configurational arrays of hydroxyapatite nanocrystals on bio-organics. Biomaterials 2001, 22, 2843-2847. [CrossRef]

38. Wang, Y.; Azaïs, T.; Robin, M.; Vallée, A.; Catania, C.; Legriel, P.; Pehau-Arnaudet, G.; Babonneau, F.; Giraud-Guille, M.-M.; Nassif, N. The predominant role of collagen in the nucleation, growth, structure and orientation of bone apatite. Nat. Mater. 2012, 11, 724-733. [CrossRef] [PubMed]

39. Landis, W.J.; Silver, F.H. Mineral Deposition in the Extracellular Matrices of Vertebrate Tissues: Identification of Possible Apatite Nucleation Sites on Type I Collagen. Cells Tissues Organs 2009, 189, 20-24. [CrossRef]

40. Silver, F.H.; Landis, W.J. Deposition of apatite in mineralizing vertebrate extracellular matrices: A model of possible nucleation sites on type I collagen. Connect. Tissue Res. 2011, 52, 242-254. [CrossRef]

41. Glimcher, M.J.; Hodge, A.J.; Schmitt, F.O. Macromolecular Aggregation States In Relation To Mineralization: The Collage-Hydroxyapatite System As Studied In Vitro. Proc. Natl. Acad. Sci. USA 1957, 43, 860-867. [CrossRef]

42. Hu, Y.-Y.; Rawal, A.; Schmidt-Rohr, K. Strongly bound citrate stabilizes the apatite nanocrystals in bone. Proc. Natl. Acad. Sci. USA 2010, 107, 22425-22429. [CrossRef]

43. Davies, E.; Muller, K.H.; Wong, W.C.; Pickard, C.J.; Reid, D.G.; Skepper, J.N.; Duer, M.J. Citrate bridges between mineral platelets in bone. Proc. Natl. Acad. Sci. USA 2014, 111, E1354-E1363. [CrossRef] [PubMed]

44. Iafisco, M.; Ramírez-Rodríguez, G.B.; Sakhno, Y.; Tampieri, A.; Martra, G.; Gómez-Morales, J.; Delgado-López, J.M. The growth mechanism of apatite nanocrystals assisted by citrate: Relevance to bone biomineralization. CrystEngComm 2015, 17, 507-511. [CrossRef]

45. Cantaert, B.; Beniash, E.; Meldrum, F.C. The role of poly(aspartic acid) in the precipitation of calcium phosphate in confinement. J. Mater. Chem. B. 2013, 1, 6586. [CrossRef] [PubMed]

46. Cantaert, B.; Beniash, E.; Meldrum, F.C. Nanoscale Confinement Controls the Crystallization of Calcium Phosphate: Relevance to Bone Formation. Chem.-Eur. J. 2013, 19, 14918-14924. [CrossRef] [PubMed]

47. Nassif, N.; Martineau, F.; Syzgantseva, O.; Gobeaux, F.; Willinger, M.; Coradin, T.; Cassaignon, S.; Azaïs, T.; Giraud-Guille, M.M. In Vivo Inspired Conditions to Synthesize Biomimetic Hydroxyapatite. Chem. Mater. 2010, 22, 3653-3663. [CrossRef]

48. Yesinowski, J.P.; Eckert, H. Hydrogen environments in calcium phosphates: Proton MAS NMR at high spinning speeds. J. Am. Chem. Soc. 1987, 109, 6274-6282. [CrossRef]

49. Wilson, E.E.; Awonusi, A.; Morris, M.D.; Kohn, D.H.; Tecklenburg, M.M.; Beck, L.W. Highly Ordered Interstitial Water Observed in Bone by Nuclear Magnetic Resonance. J. Bone Miner. Res. 2004, 20, 625-634. [CrossRef]

50. Cowin, S.C. Bone poroelasticity. J. Biomech. 1999, 32, 217-238. [CrossRef]

51. Neuman, W.F.; Toribara, T.Y.; Mulryan, B.J. The Surface Chemistry of Bone. VII. The Hydration Shell ${ }^{1}$. J. Am. Chem. Soc. 1953, 75, 4239-4242. [CrossRef]

52. Drouet, C.; Aufray, M.; Rollin-Martinet, S.; Vandecandelaère, N.; Grossin, D.; Rossignol, F.; Champion, E.; Navrotsky, A.; Rey, C. Nanocrystalline apatites: The fundamental role of water. Am. Mineral. 2018, 103, 550-564. [CrossRef]

53. Rey, C.; Combes, C.; Drouet, C.; Sfihi, H.; Barroug, A. Physico-chemical properties of nanocrystalline apatites: Implications for biominerals and biomaterials. Mater. Sci. Eng. C 2007, 27, 198-205. [CrossRef]

54. Cazalbou, S.; Combes, C.; Eichert, D.; Rey, C.; Glimcher, M.J. Poorly crystalline apatites: Evolution and maturation in vitro and in vivo. J. Bone Miner. MeTable 2004, 22. [CrossRef]

55. Neuman, W.F.; Neuman, M.W. The Nature of the Mineral Phase of Bone. Chem. Rev. 1953, 53, 1-45. [CrossRef]

56. Su, X.; Sun, K.; Cui, F.Z.; Landis, W.J. Organization of apatite crystals in human woven bone. Bone 2003, 32, 150-162. [CrossRef]

57. Vandecandelaere, N.; Rey, C.; Drouet, C. Biomimetic apatite-based biomaterials: On the critical impact of synthesis and post-synthesis parameters. J. Mater. Sci. Mater. Med. 2012, 23, 2593-2606. [CrossRef] [PubMed] 
58. Tao, J.; Pan, H.; Zeng, Y.; Xu, X.; Tang, R. Roles of Amorphous Calcium Phosphate and Biological Additives in the Assembly of Hydroxyapatite Nanoparticles. J. Phys. Chem. B 2007, 111, 13410-13418. [CrossRef]

59. De Yoreo, J.J.; Gilbert, P.U.P.A.; Sommerdijk, N.A.J.M.; Penn, R.L.; Whitelam, S.; Joester, D.; Zhang, H.; Rimer, J.D.; Navrotsky, A.; Banfield, J.F.; et al. Crystallization by particle attachment in synthetic, biogenic, and geologic environments. Science 2015, 349, 6760. [CrossRef]

60. Penn, R.L.; Banfield, J.F. Imperfect Oriented Attachment: Dislocation Generation in Defect-Free Nanocrystals. Science 1998, 281, 969-971. [CrossRef] [PubMed]

61. Jäger, I.; Fratzl, P. Mineralized Collagen Fibrils: A Mechanical Model with a Staggered Arrangement of Mineral Particles. Biophys. J. 2000, 79, 1737-1746. [CrossRef]

62. Duer, M.; Veis, A. Water brings order: Bone mineralization. Nat. Mater. 2013, 12, 1081-1082. [CrossRef] [PubMed]

63. Huang, S.-J.; Tsai, Y.-L.; Lee, Y.-L.; Lin, C.-P.; Chan, J.C.C. Structural Model of Rat Dentin Revisited. Chem. Mater. 2009, 21, 2583-2585. [CrossRef]

64. Von Euw, S.; Zhang, Q.; Manichev, V.; Murali, N.; Gross, J.; Feldman, L.C.; Gustafsson, T.; Flach, C.; Mendelsohn, R.; Falkowski, P.G. Biological control of aragonite formation in stony corals. Science 2017, 356, 933-938. [CrossRef] [PubMed]

65. Nassif, N.; Pinna, N.; Gehrke, N.; Antonietti, M.; Jager, C.; Colfen, H. Amorphous layer around aragonite platelets in nacre. Proc. Natl. Acad. Sci. USA 2005, 102, 12653-12655. [CrossRef] [PubMed]

66. Benzerara, K.; Menguy, N.; Lopez-Garcia, P.; Yoon, T.-H.; Kazmierczak, J.; Tyliszczak, T.; Guyot, F.; Brown, G.E. Nanoscale detection of organic signatures in carbonate microbialites. Proc. Natl. Acad. Sci. USA 2006, 103, 9440-9445. [CrossRef] [PubMed]

(C) 2018 by the authors. Licensee MDPI, Basel, Switzerland. This article is an open access article distributed under the terms and conditions of the Creative Commons Attribution (CC BY) license (http:/ / creativecommons.org/licenses/by/4.0/). 